\title{
On the Issue of Increasing Carbon Dioxide Concentrations and Global Climate Change
}

\section{Frederick House}

Department of Physics, Drexel University, Philadelphia, PA 19104, USA

\section{Abstract}

Greenhouse gases, in particular carbon dioxide, are responsible for warming the earth's climate making the planet habitable for mankind. The physics of this warming is unquestioned. The problem is that evidence of warming is not evidence of what causes warming. But how do GHG impact the climate and by how much? This paper examines the relation between $\mathrm{CO}_{2}$ increases and global temperatures.

\section{Publication History:}

Received: July 06, 2016

Accepted: November 08, 2016

Published: November 10, 2016

Keywords:

Carbon dioxide, Greenhouse gases, Climate changes, Temperature

\section{Background}

Both natural and anthropogenic drivers cause changes in the Earth's climate. Crowley [1] states that prior to the Industrial Revolution (pre -1850) 41 to $64 \%$ of decadal scale temperature variations were due to changes in solar radiation and volcanism.

Budyko [2] studied "The Effect of Solar Radiation Variations on the Climate of the Earth." He concludes that secular variations of the mean temperature of the Earth can be explained by variations in short-wave radiation arriving at the surface. He found that comparatively small variations in atmospheric transparency could be sufficient for the development of quaternary glaciations.

Robock [3] wrote an extensive review article on "Volcanic Eruptions and Climate." In a few days after an eruption, the amplitude of the diurnal cycle of surface air temperature is reduced under the cloud. On a much larger time scale, volcanic effects played a major role in climate change during the Little Ice Age.

After 1850, anthropogenic drivers of the climate (namely, $\mathrm{CO}_{2}$, $\mathrm{CH}_{4}$ and $\mathrm{N}_{2} \mathrm{O}$ ) became steadily more important than natural climate drivers. Crowley's model indicates that only about $25 \%$ of the $20^{\text {th }}$. century temperature increase can be attributed to natural variability.

Working Group 1 [4]: The Physical Science Basis - of the IPCC Fifth Assessment Report states that the warming of the climate system is unprecedented since the 1950s. The linear trend line through the HadCRUT4 data in figure 1 indicates a temperature increase of $0.8^{\circ} \mathrm{C}$ from 1850 through 2014 . The largest contribution to total radiation forcing at the surface during the $20^{\text {th }}$ Century is caused by increased atmospheric concentrations of $\mathrm{CO}_{2}$.

In general, climate scientists look at global warming as a time series of increasing temperature anomalies along with a separate time series of increasing $\mathrm{CO}_{2}$. Can changes in $\mathrm{CO}_{2}$ alone explain temperature anomalies, both of which are treated as singular functions in time? This process seems to be a fault in their analysis procedures.

To illustrate this point, figure 2 is a time series of $\mathrm{CO}_{2}$ increases since $(1850-2014)$ and Figure 1 shows the global temperature anomalies of the Earth for the same period. Both graphs are singular functions in time. It is evident from the graphs that $\mathrm{CO}_{2}$ increases seem to mirror the variations in temperature. However, if the scale of Figure 2 was changed, a good comparison would be lacking. Certainly both graphs indicate increasing magnitudes in time, and since $\mathrm{CO}_{2}$ is a GHG, there is a physical coupling. The logic appears to be sound.

\section{Cross Correlation Formulation}

Cross correlation is a standard method of estimating the degree to which two series are correlated. Consider two series $\mathrm{X}$ (i) and $\mathrm{Y}(\mathrm{i})$ where $\mathrm{I}=0,1,2 \ldots \mathrm{N}-1$. The cross correlation coefficient $\rho$ is defined as $\rho(\mathrm{X}, \mathrm{Y})=\sum_{\mathrm{i}}[(\mathrm{X}(\mathrm{i})-\mathrm{mx}) *(\mathrm{Y}(\mathrm{i})-\mathrm{mY})]$ devided by $\sigma_{\mathrm{X}} * \sigma_{\mathrm{Y}}$

$\mathbf{m X}$ and $\mathbf{m Y}$ are means of their corresponding series and $\boldsymbol{\sigma}_{\mathrm{X}}$ and $\sigma_{Y}$ are their respective standard deviations. The denominator in Eq. (1) serves to normalize the correlation coefficients such that $(-1<=$ $\boldsymbol{\rho}(\mathrm{X}, \mathrm{Y})<=+\mathbf{1})$, the bounds indicating maximum correlation and 0 indicating no correlation. Also Eq. (1) assumes the time delay is zero. The term $\mathbf{R}^{2}$ is defined herein as the square of the correlation coefficient $\left(\rho^{2}\right)$ and is a measure of how much the variance of $\mathbf{Y}(\mathbf{i})$ is explained by the variance of $\mathbf{X}(\mathbf{i})$.

Calculations utilized the CORREL function of MS Excel spread sheets. The CORREL function is identical to Eq. (1).

\section{Correlation of Temperature Anomalies with Increases of $\mathrm{CO}_{2}$ Concentration}

How much does an increases in $\mathrm{CO}_{2}$ concentrations explain the record of global temperature warming? To determine this, data in Figure 1 are cross correlated with the HadCRUT4 data of figure 2 over the same period (1850 to 2014)

Calculations for global data indicate a correlation of $\boldsymbol{\rho}=\mathbf{0 . 6 9 1}$ and $\mathbf{R}^{2}$ $=\mathbf{4 8} \%$., for the Northern Hemisphere $\boldsymbol{\rho}=\mathbf{0 . 6 8 3}$ and $\mathrm{R}^{2}=47 \%$ and for the Southern Hemisphere, $\rho=\mathbf{0 . 6 6 2}$ and $\mathrm{R}^{2}=\mathbf{4 4 \%}$.

"Corresponding Author: Prof. Frederick House, Department of Physics, Drexel University, Philadelphia, PA 19104, USA; E-mail: house@drexel.edu

Citation: House F (2016) On the Issue of Increasing Carbon Dioxide Concentrations and Global Climate Change. Int J Earth Environ Sci 1: 120. doi: https://doi.org/10.15344/2456-351X/2016/120

Copyright: () 2016 House. This is an open-access article distributed under the terms of the Creative Commons Attribution License, which permits unrestricted use, distribution, and reproduction in any medium, provided the original author and source are credited. 
Citation: House F (2016) On the Issue of Increasing Carbon Dioxide Concentrations and Global Climate Change. Int J Earth Environ Sci 1: 120. doi: https://doi. org/10.15344/2456-351X/2016/120

Page 2 of 5

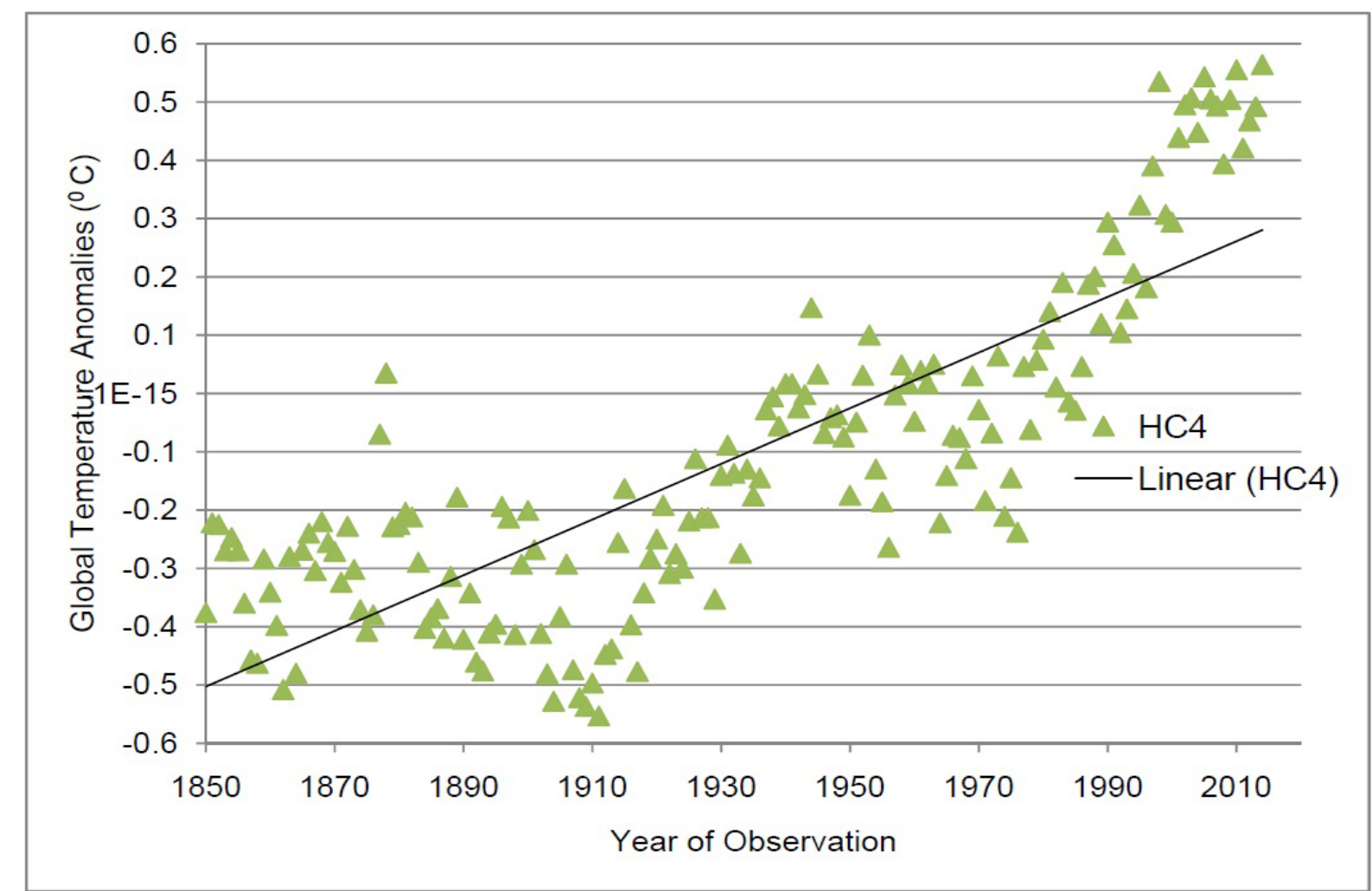

Figure 1: Plot of Temperature Anomalies from the HadCRUT4 Data Set - (UK) - URL(1)

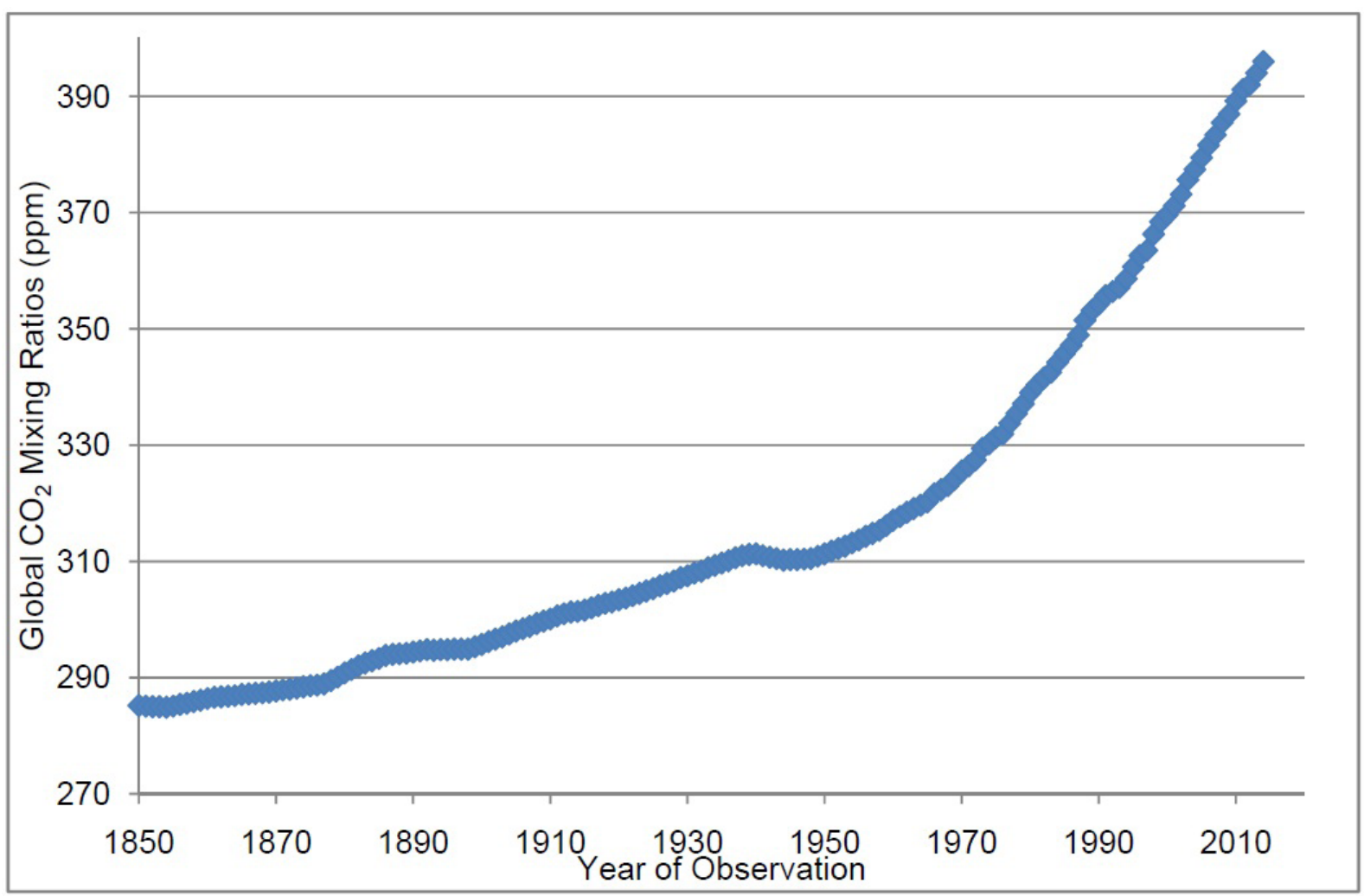

Figure 2: Global Increase in Carbon Dioxide from NASA GISS Data Set - (US) - URL(2). 
Citation: House F (2016) On the Issue of Increasing Carbon Dioxide Concentrations and Global Climate Change. Int J Earth Environ Sci 1: 120. doi: https://doi. org/10.15344/2456-351X/2016/120

Page 3 of 3

$\mathbf{R}^{\mathbf{2}}$ values indicate that less than $50 \%$ of the variance of global temperatures is explained by the variance of $\mathrm{CO}_{2}$ concentrations. These results are important in understanding the contribution of $\mathrm{CO}_{2}$ to the global warming picture.

\section{Concluding Remarks}

Both anthropogenic and natural drivers of the Earth's climate affect the temperature anomalies of the HadCRUT4 data set. Thus, the total variance $(100 \%)$ may be explained by these two factors. In round numbers, $50 \%$ of the variance is explained by $\mathrm{CO}_{2}$ increases, and perhaps an additional $10 \%$ may be due to other greenhouse gases. The $40 \%$ of the variance that remains may be attributed to natural climate drivers such as volcanic activity, solar variations, El Nino cycles, coming out of the Little Ice Age, pollution particulates, etc. The $40 \%$ value is in keeping with Crowley's estimate of $25 \%$ for the $20^{\text {th }}$ century.

This partitioning of variances is illustrated in figure 3 .

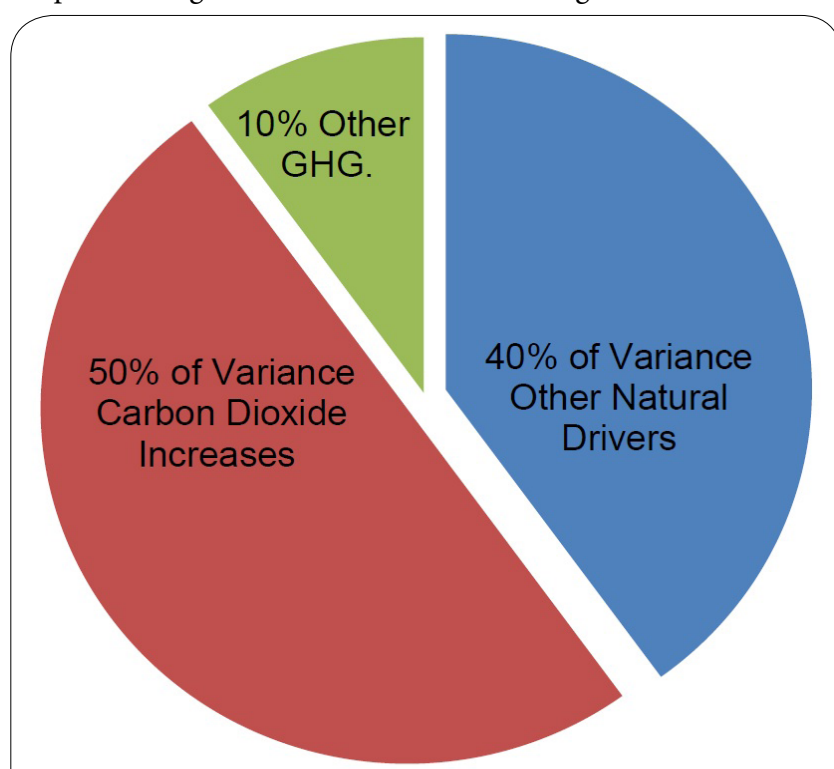

Figure 3: Partitioning of Variances for Temperature Anomalies HadCRUT4 Data Set.

There is a lack of robust correlation between the increase in $\mathrm{CO}_{2}$ emissions and global temperature rise. If global warming is caused primarily by manmade increases in $\mathrm{CO}_{2}$, why is there not a 0.90 correlation? In conclusion, evidence of warming is not evidence of what causes the warming.

\section{Abbreviations}

GISS: Goddard Institute for Space Studies

MS: Microsoft Corporation

NASA: National Aeronautics and Space Administration

UK: United Kingdom

US: United States

\section{Acknowledgment}

Thanks go to my daughter Mary Elizabeth who helped greatly in editing this manuscript.

\section{References}

1. Crowley TJ (2000) Causes of Climate Change Over the Past 1000 Years Science 289: $270-277$.

Int J Earth Environ Sci

ISSN: $2456-351 \mathrm{X}$
2. Budyko MI (1969) The Effect of Solar Radiation on the Climate of the Earth. Tellus 5: 611-619.

3. Robock A (2000) Volcanic Eruptions and Climate. Reviews of Geophysics, AGU 38: 191- 219.

4. Working Group 1: The Physical Science Basis. IPCC Fifth Assessment Report, Summary for Policy Makers, 27 Sept 2013.

5. http://cdiac.ornl.gov/ftp/trends/temp/jonescru/global.txt

6. http://data.giss.nasa.gov/modelforce/ghgases/Fig1A.ext.txt 